\title{
Análise bibliométrica sobre o Cerrado na base de dados Web Of Science
}

Bibliometric analysis of the Cerrado biome in the Web Of Science database

Análisis bibliométrica sobre el Biome Cerrado en la base de datos Web Of Science

Alícia Mendonça Kneubil

Bacharelanda em Gestão de Políticas Públicas na Universidade de São Paulo aliciamkneubil@gmail.com | alicia.mk@usp.br

Luiz Henrique Vieira da Silva Mestrando no Programa de Pós-Graduação Stricto Sensu em Sustentabilidade da PUC-Campinas vieiraluiz77@gmail.com | luiz.hvs@puccampinas.edu 


\title{
Revista Científica ANAP Brasil
}

\author{
ISSN 1984-3240 - Volume 13, número 31, 2020
}

RESUMO

O Brasil é considerado o país com a maior biodiversidade do planeta. Dentre seus biomas, o Cerrado desponta como um dos mais ricos e singulares, cobrindo $22 \%$ do território nacional e apresentando espécies únicas de árvores, plantas e animais. No entanto, a atividade antrópica sobre esse ecossistema natural tem gerado problemas como o desmatamento e a emissão de poluentes no solo e na atmosfera. Observando o avanço das cidades sobre o bioma e a crescente necessidade de políticas públicas voltadas à preservação da sua fauna e flora, capazes de aproveitar o capital natural disponível de maneira sustentável, este artigo destacou, por meio de uma pesquisa básica, de abordagem mista e procedimento exploratório, com resultados obtidos via análise bibliométrica, a produção científica sobre o Cerrado na base de dados Web of Science, no período que compreende 1960 e 2019. Constatou-se que os artigos publicados concentram-se na área das ciências biológicas, evidenciando uma lacuna de pesquisa para que acadêmicos das ciências sociais aplicadas direcionem o olhar a esse bioma, no sentido de traçar alternativas à depleção de seus recursos naturais e aos problemas gerados pela urbanização, permitindo o florescimento do desenvolvimento sustentável aplicado ao Cerrado, tanto ao seu meio ambiente natural, quanto às suas populações.

PALAVRAS-CHAVE: Cerrado, políticas públicas, biodiversidade, reparação ecossistêmica, bibliometria.

\section{ABSTRACT}

Brazil is considered the most biodiverse country on the planet. Among its biomes, the Cerrado emerges as one of the richest and most unique, covering $22 \%$ of the national territory and presenting unique species of trees, plants, and animals. However, human activity on this natural ecosystem has created problems such as deforestation and the emission of pollutants in the soil and in the atmosphere. Observing the advance of cities over the biome and the growing need for public policies aimed at the preservation of their fauna and flora, capable of taking advantage of the available natural capital in a sustainable manner, this article highlighted, through a basic research, with a mixed approach and exploratory procedure, with results obtained through bibliometric analysis, the scientific production on the Cerrado in the Web of Science database, in the period between 1960 and 2019. It was found that the articles published are concentrated in the area of biological sciences, evidencing a research gap so that academics of applied social sciences direct their gaze to this biome, in order to outline alternatives to the depletion of their natural resources and the problems generated by urbanization, allowing the flourishing of sustainable development applied to the Cerrado, both in its environment natural, as to their populations.

KEYWORDS: Cerrado, public policies, biodiversity, ecosystem repair, bibliometrics.

\section{RESÚMEN}

Brasil es considerado el país con mayor biodiversidad del planeta. Entre sus biomas, el Cerrado emerge como uno de los más ricos y únicos, cubriendo el $22 \%$ del territorio nacional y presentando especies únicas de árboles, plantas y animales. Sin embargo, la actividad humana en este ecosistema natural ha creado problemas como la deforestación y la emisión de contaminantes en el suelo y en la atmósfera. Observando el avance de las ciudades sobre el bioma y la creciente necesidad de políticas públicas dirigidas a la preservación de su fauna y flora, capaces de aprovechar el capital natural disponible de manera sostenible, este artículo destacó, a través de una investigación básica, con un enfoque mixto y procedimiento exploratorio, con resultados obtenidos a través del análisis bibliométrico, la producción científica en el Cerrado en la base de datos de la Web of Science, en el período comprendido entre 1960 y 2019. Se encontró que los artículos publicados se concentran en el área de las ciencias biológicas, evidenciando una brecha de investigación para que los académicos de las ciencias sociales aplicadas dirijan su mirada a este bioma, para delinear alternativas al agotamiento de sus recursos naturales y los problemas generados por la urbanización, permitiendo el florecimiento del desarrollo sostenible aplicado al Cerrado, tanto en su entorno natural, en cuanto a sus poblaciones.

PALABRAS-CLAVE: Cerrado, políticas públicas, biodiversidad, reparación de ecosistemas, bibliometría. 


\section{INTRODUÇÃO}

O Brasil é considerado o país com a maior biodiversidade do planeta (MINISTÉRIO DO MEIO AMBIENTE, 2020a), com uma fauna e flora variadas, estendendo-se por suas dimensões continentais de maneira ímpar. Seu território abriga seis biomas de características distintas e singulares, a saber: Amazônia, Caatinga, Cerrado, Mata Atlântica, Pampa e Pantanal.

O segundo maior deles, o Cerrado, historicamente tem sofrido devido à ação antrópica, calcada na exploração de suas riquezas naturais há mais de cinco séculos. Por conseguinte, estudos recentes confirmam que esse bioma é um dos mais afetados pela ocupação humana e, sobremaneira, pelo paradigma dominante de crescimento econômico.

Recentemente, observando o avanço das médias e grandes cidades sobre os ecossistemas naturais e a necessidade de políticas públicas para conservá-los, concomitantemente, aproveitar o capital natural disponível sem que isso acarrete em sua depleção, percebe-se que, por ser capaz de diagnosticar a situação do meio ambiente natural e traçar linhas de ação orientadas a um desenvolvimento que seja genuinamente sustentável, a Academia desponta como importante aliada aos entes governamentais e às organizações do terceiro setor empenhadas no referido bioma.

Sendo assim, este artigo debruçou-se sobre a produção científica nacional e internacional que envolve o Cerrado. Utilizou-se, para tanto, a base de dados Web of Science, tomando como recorte temporal o período que compreende 1960 e 2019.

\section{METODOLOGIA}

O método da pesquisa caracteriza-se, quanto à abordagem do problema, como básico e quantitativo. A pesquisa básica destina-se à geração de novos conhecimentos, sem uma previsão de sua aplicação prática, ao passo que a quantitativa se baseia em variáveis "que resultam de mensurações (contínuas) e aquelas que resultam de contagens (discretas)" (CEBRAP, 2016, p. 20).

Em relação ao tipo, enquadra-se como descritivo, que, por sua vez, tem por objetivo primordial o "estabelecimento de relações entre variáveis" (GIL, 2008, p. 27).

Para obtenção dos dados, optou-se pela análise bibliométrica. Quevedo-Silva et al. (2016) apontam que o uso dessa técnica é uma prática frequente nas pesquisas em ciências sociais aplicadas. Nesse campo, "os estudos bibliométricos se concentram em examinar a produção de artigos em um determinado campo de saber, mapear as comunidades acadêmicas e identificar as redes de pesquisadores e suas motivações" (CHUEKE; AMATUCCI, 2015, p. 2).

Esse método faz uso de algumas leis, batizadas com os nomes de seus precursores. Por essa razão, destaca-se que no presente artigo fez-se uso da Lei de Bradford, que relaciona a dispersão de artigos por periódicos (QUEVEDO-SILVA et al., 2016, p. 249). 


\title{
3. REFERENCIAL TEÓRICO
}

\subsection{Cerrado}

De acordo com o Ministério do Meio Ambiente (2020b, s. p.), "o Cerrado é o segundo maior bioma da América do Sul, ocupando uma área de $2.036 .448 \mathrm{~km}^{2}$, se consideradas as zonas de transição desse bioma com os seus adjacentes. Essa soma equivale a cerca de $22 \%$ do território nacional.

Conforme demonstra a Figura 1, sua área contínua incide sobre os estados de Goiás, Tocantins, Mato Grosso, Mato Grosso do Sul, Minas Gerais, Bahia, Maranhão, Piauí, Rondônia, Paraná, São Paulo e Distrito Federal, além dos encraves no Amapá, Roraima e Amazonas, que não estão destacados no mapa.

\section{Figura 1: Extensão geográfica do bioma Cerrado (em amarelo) no território brasileiro}

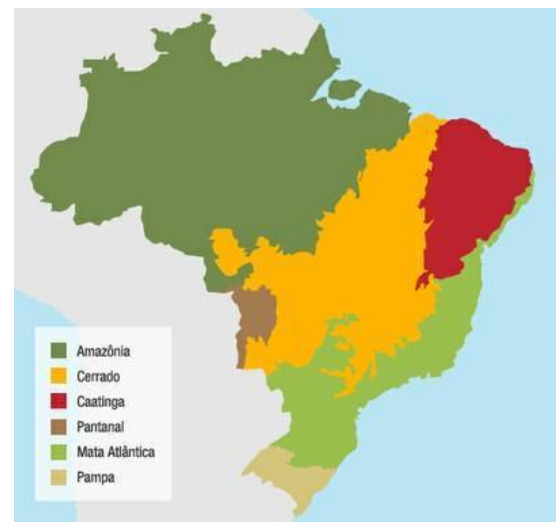

Fonte: Ministério do Meio Ambiente (2007).

Em relação à sua biodiversidade, o Ministério do Meio Ambiente (2020b, s. p.) destaca que

\begin{abstract}
do ponto de vista da diversidade biológica, o Cerrado brasileiro é reconhecido como a savana mais rica do mundo, abrigando 11.627 espécies de plantas nativas já catalogadas. Existe uma grande diversidade de habitats, que determinam uma notável alternância de espécies entre diferentes fitofisionomias. Cerca de 199 espécies de mamíferos são conhecidas, e a rica avifauna compreende cerca de 837 espécies. Os números de peixes (1200 espécies), répteis (180 espécies) e anfíbios (150 espécies) são elevados. 0 número de peixes endêmicos não é conhecido, porém os valores são bastante altos para anfíbios e répteis: $28 \%$ e $17 \%$, respectivamente. De acordo com estimativas recentes, o Cerrado é o refúgio de $13 \%$ das borboletas, $35 \%$ das abelhas e $23 \%$ dos cupins dos trópicos.
\end{abstract}

Ainda que muitas pessoas reconheçam as inegáveis riquezas naturais do Cerrado e a necessidade latente do reconhecimento desse bioma como Patrimônio Nacional, nem sempre foi esse o pensamento da classe política brasileira. Nos anos 1960, diante de espectro desenvolvimentista que imperava no país, o planejamento e a construção de Brasília em uma região dominada pelo bioma supracitado foram apenas promessas do progresso que viria. 
Essa época corresponde aos fundamentos do ambientalismo, na Europa ocidental e nos Estados Unidos da América, fazendo com que parte considerável do apelo da produção científica da época estivesse alinhada à chamada Questão Ambiental, tema que ganhou importância social, política e econômica (SOCIEDADE BRASILEIRA DE ECONOMIA ECOLÓGICA, 2020). Entretanto, Georgescu-Roegen (2012, p. 73) adverte que "ao consultar os periódicos econômicos do mundo anglófono anteriores a 1950, [...] não se encontram muitas referências ao 'desenvolvimento econômico'”. Depreende-se, então, que a visão desenvolvimentista estava alicerçada na ideia de crescimento econômico ${ }^{1}$.

Além disso, devido à chamada "Revolução Verde" dos anos 1970, "novas técnicas agronômicas somadas à alta demanda do mercado e os incentivos do Estado abriram uma nova fase de devastação do Cerrado" (DELLA GIUSTINA, 2013, p. 192).

Sendo assim, para que as metas de crescimento fossem atingidas, grande parte do ambiente natural precisou ser alterado, ainda que o processo de ocupação histórica da região demonstre que a região abrigou desbravadores e exploradores de riquezas minerais desde o período Colonial. Todavia, sublinha-se que, no Século XX, a pressão antrópica sobre o Cerrado e, especialmente sobre o solo, tornou-se cada vez mais emergente (DELLA GIUSTINA, 2013).

Atualmente, a vegetação do Cerrado, em grande parte de sua extensão, encontra-se quase desertificada, suas árvores baixas, esparsas e com troncos retorcidos foram substituídas por enormes plantações de soja, milho, algodão e pastagens de manejo inapropriado, prejudicando essencialmente o solo e os lençóis freáticos, lençóis estes responsáveis por dar origem às principais bacias hidrográficas da América Latina. Quanto à população que habita esse bioma, destaca-se a do Distrito Federal, programada inicialmente para ser composta por 500 mil pessoas, mas que hoje conta com quase cinco vezes esse montante, apresentando profundas iniquidades socioeconômicas (AGÊNCIA BRASIL, 2018) e exercendo uma considerável pressão sobre o ecossistema natural.

Posto isso, é perceptível que o tão sonhado progresso de JK nunca aconteceu. Na terra prometida de prosperidade econômica e modernidade, hoje compartilham a mesma paisagem a riqueza, o poder e, em contrapartida, problemas de infraestrutura, miséria, desigualdades sociais e degradação ambiental. Essa realidade só será transformada a partir da percepção de que a vida humana e o meio ambiente devem coexistir harmoniosamente. Para isso, são necessárias políticas públicas multilaterais orientadas pelo e para o desenvolvimento sustentável, definido no Relatório "Nosso Futuro Comum" como "aquele que atende às necessidades do presente sem comprometer a possibilidade de as gerações futuras atenderem a suas próprias necessidades" (WORLD COMMISSION ON ENVIRONMENT AND DEVELOPMENT, 1987, p. 43).

\footnotetext{
${ }^{1}$ Daly (2004) afirma que o crescimento sustentável é impossível, pois a própria ideia de crescimento não pode ser considerada sustentável. Em detrimento a isso, propõe o desenvolvimento como uma transformação cultural e prática, distanciando-se do crescimento, antigo paradigma econômico.
} 


\subsection{Pressão humana sobre o Cerrado}

Dados da organização não governamental internacional WWF (2020, s. p.) apontam que, "depois da Mata Atlântica, o Cerrado é o ecossistema brasileiro que mais alterações sofreu com a ocupação humana". O problema decorre de atividades como a mineração, a agricultura e a pecuária (WWF, 2020, s. p.).

Em adição, além de Brasília e do Distrito Federal, importantes aglomerados urbanos despontam no Cerrado, como Goiânia, Palmas e suas respectivas regiões metropolitanas, imprimindo uma devastadora pressão no meio ambiente.

A abordagem ecológica e biofísica da economia, baseada na 2a Lei da Termodinâmica, configura a ideia de que "o processo econômico não faz nada além de transformar recursos naturais de valor (baixa entropia) em resíduos (alta entropia)" (GEORGESCU-ROEGEN, 2012, p. 62). Sendo assim, depreende-se que a manutenção das atividades produtivas e da malha urbana e dos transportes em um determinado ecossistema natural impactam o meio ambiente de forma brutal e irreversível, ao comprometer recursos naturais e ao gerar resíduos sólidos, esgoto, escapes de automóveis e da atividade industrial, dentre outros poluidores.

Os dados referentes ao bioma estudado apontam exatamente nessa direção: "cerca de $80 \%$ do Cerrado já foi modificado pelo homem por causa da expansão agropecuária, urbana e construção de estradas" e "somente 19,15\% corresponde a áreas nas quais a vegetação original ainda está em bom estado" (WWF, 2020, s. p.).

Esse cenário, portanto, exige políticas públicas capazes de reverter o aparentemente consolidado processo de esgotamento dos recursos naturais e os prejudiciais desdobramentos socioeconômicos nas cidades assentadas sobre o Cerrado.

\subsection{Políticas públicas de conservação do Cerrado}

Na ótica de Kingdon (2014), pensar o mundo das políticas públicas significa analisar qual ator ou grupo será beneficiado com as ações do Estado, em que momento e circunstância há essa troca, e quais são os meios para que ela aconteça. Cabe, então, questionar por quais razões alguns problemas entram ou não nas discussões do governo, e como algumas ideias transformam-se em problemas e passam a integrar o pensamento dos formuladores de políticas públicas.

Nesse sentido, torna-se fundamental estabelecer uma distinção entre um problema e uma questão. Para Kingdon (2014), um problema só pode ser considerado como tal a partir do instante em que adentra o conjunto de assuntos sobre os quais o governo concentra sua atenção em um determinado momento, ou seja, a agenda governamental. Até que isso aconteça, o problema é visto apenas como questão, uma situação de conflito que necessita do olhar do Estado para ser alterada. No entanto, o autor alerta que os problemas não são binários. Em outras palavras, a criação de um problema não implica necessariamente em uma solução; na verdade, em grande parte esse processo dá-se de maneira contrária, uma vez que os recursos orçamentários e operacionais são escassos e, por isso, os gestores escolhem o problema a ser enfrentado a partir das capacidades administrativas já existentes.

Outro aspecto importante para esta análise são os modelos de fluxos colocados pelo autor, condicionantes para que a política pública aconteça. De maneira objetiva, são eles: o fluxo dos 


\section{Revista Científica ANAP Brasil}

ISSN 1984-3240 - Volume 13, número 31, 2020

problemas, composto por indicadores, eventos e crises, e avaliações de políticas públicas já existentes; o fluxo de soluções, onde encontram-se os gestores, a Academia, os grupos de interesse, os servidores públicos, dentre outros atores; e o fluxo político, responsável pelas trocas, negociações e barganhas políticas, no qual estão os acordos de interesses para que determinado problema entre ou não na agenda.

Assim, é através da convergência simultânea desses três fluxos, impulsionada pelos empreendedores de políticas públicas - atores ou grupo de pessoas que cuja função principal é a defesa uma ideia - que uma janela de oportunidade é criada e a questão terá acesso à agenda governamental, tornando-se, então, um problema e possibilitando a política pública (KINGDON, 2014). A necessidade de políticas públicas de conservação do Cerrado já constituiu um problema nas agendas governamentais, mas atualmente figura exclusivamente como uma questão socioambiental.

Como exemplo, destaca-se o reconhecimento do Cerrado como Patrimônio Nacional, algo que seria fundamental para que sua área e seus recursos naturais fossem utilizados mediante a conservação dos ecossistemas, em consonância com o desenvolvimento sustentável. Apesar da aprovação da Proposta de Emenda Constitucional (PEC) 504/2010 no Senado Federal, que altera o parágrafo 4을 do art. 225 da Constituição Federal e destina-se a incluir o Cerrado e a Caatinga entre os biomas considerados patrimônio nacional (BRASIL, 2010), sobreleva-se que a mesma ainda não entrou em vigor, pois está sujeita à apreciação do Plenário da Câmara dos Deputados desde então.

Della Giustina (2013, p. 164) aponta que "a conservação da natureza como política pública, no estado de Goiás, é relativamente recente, quando comparada às políticas desenvolvimentistas", tendo em vista que as primeiras Unidades de Conservação (UC) no estado foram criadas somente em 1961, a saber, o Parque Nacional da Chapada dos Veadeiros e o Parque Nacional das Emas, quase 30 anos após as primeiras unidades brasileiras.

Finalmente, Souza (2006) salienta que as políticas públicas não são formuladas e implementadas apenas pela administração pública. Além dos governos, empresas, organizações do terceiro setor, instituições religiosas, sindicatos, associações, fundações, institutos, universidades e indivíduos sem organização formal podem influir nesse complexo jogo de interesses que permeiam a formação da agenda governamental.

Por isso, o reconhecimento da ação acadêmica como ator que desenvolve soluções para as adversidades e provações enfrentadas por esse bioma, bem como o papel de empreendedora na defesa dessas pautas, deve ser realçado. Fernandes e Pessôa (2011, p. 32) corroboram com essa afirmação ao apontarem que

\footnotetext{
a primeira etapa para amenizar a perda do Cerrado, ou até mesmo retardar, seria superar o desconhecimento do Cerrado no Brasil e no exterior, estimulando o conhecimento principalmente entre os governantes. Pesquisas científicas deverão ser estimuladas, os conhecimentos deverão ser amplamente difundidos entre a sociedade, através dos meios de comunicações e nas escolas.
}

Com base nessa afirmação, no próximo tópico há um levantamento bibliométrico sobre a produção científica que envolveu o Cerrado e que pode fomentar a elaboração e, consequentemente, a execução de políticas públicas nesse sentido. 


\section{RESULTADOS E DISCUSSÃO}

Neste capítulo, os resultados da bibliometria foram analisados, permitindo uma discussão entre os dados obtidos e o referencial teórico supracitado.

Inicialmente, a pesquisa abordou a produção científica anual sobre o bioma Cerrado por ano na base Web of Science. Para tanto, o termo "Cerrado" foi pesquisado na categoria "tópico", que considera, das publicações, o título, o resumo, as palavras-chave de seus respectivos autores e o Keywords Plus, totalizando 7498 artigos publicados no período que compreende 1960, data da primeira menção a esse termo nos periódicos da base, e 2019.

A Tabela 1 expõe a crescente na publicação de papers sobre o cerrado. Em 2019, o termo atingiu o mais alto número de menções, 729 , correspondendo a mais de $9,5 \%$ do total da série histórica.

Tabela 1: Dispersão anual da produção científica sobre o Cerrado na base Web of Science (1960-2019)

\begin{tabular}{|c|c|c|}
\hline Ano de publicação & Registros & $\%$ de 7498 \\
\hline 2019 & 729 & 9.524 \\
\hline 2018 & 702 & 9.172 \\
\hline 2017 & 672 & 8.780 \\
\hline 2016 & 662 & 8.649 \\
\hline 2015 & 570 & 7.447 \\
\hline 2014 & 472 & 6.167 \\
\hline 2013 & 513 & 6.702 \\
\hline 2012 & 450 & 5.879 \\
\hline 2011 & 453 & 5.918 \\
\hline 2010 & 335 & 4.377 \\
\hline 2009 & 278 & 3.632 \\
\hline 2008 & 284 & 3.710 \\
\hline 2007 & 213 & 2.783 \\
\hline 2006 & 177 & 2.313 \\
\hline 2005 & 129 & 1.685 \\
\hline 2004 & 120 & 1.568 \\
\hline 2003 & 91 & 1.189 \\
\hline 2002 & 73 & 0.954 \\
\hline
\end{tabular}


Revista Científica ANAP Brasil

ISSN 1984-3240 - Volume 13, número 31, 2020

\begin{tabular}{|c|c|c|}
\hline 2001 & 56 & 0.732 \\
\hline 2000 & 64 & 0.836 \\
\hline 1999 & 60 & 0.784 \\
\hline 1998 & 70 & 0.915 \\
\hline 1997 & 47 & 0.614 \\
\hline 1996 & 35 & 0.457 \\
\hline 1995 & 33 & 0.431 \\
\hline 1994 & 23 & 0.300 \\
\hline 1993 & 27 & 0.353 \\
\hline 1992 & 26 & 0.340 \\
\hline 1991 & 20 & 0.261 \\
\hline 1990 & 9 & 0.118 \\
\hline 1989 & 5 & 0.065 \\
\hline 1988 & 10 & 0.131 \\
\hline 1987 & 11 & 0.144 \\
\hline 1986 & 6 & 0.078 \\
\hline 1985 & 5 & 0.065 \\
\hline 1984 & 6 & 0.078 \\
\hline 1983 & 8 & 0.105 \\
\hline 1982 & 13 & 0.170 \\
\hline 1981 & 10 & 0.131 \\
\hline 1980 & 2 & 0.026 \\
\hline 1979 & 5 & 0.065 \\
\hline 1978 & 2 & 0.026 \\
\hline 1977 & 4 & 0.052 \\
\hline 1973 & 1 & 0.013 \\
\hline 1972 & 3 & 0.039 \\
\hline 1971 & 2 & 0.026 \\
\hline
\end{tabular}




\begin{tabular}{|r|r|r|}
\hline 1969 & 2 & 0.026 \\
\hline 1968 & 1 & 0.013 \\
\hline 1967 & 1 & 0.013 \\
\hline 1966 & 7 & 0.091 \\
\hline 1960 & 1 & 0.013 \\
\hline
\end{tabular}

Fonte: Elaborado pelos autores, com base nos dados da pesquisa.

Percebe-se que a produção acadêmica sobre o Cerrado permaneceu baixa, com poucas oscilações, no intervalo que compreende 1960 e 1988, mantendo-se assim, portanto, durante toda a ditadura militar. A partir da redemocratização e, possivelmente impulsionada por eventos globais como a publicação do Relatório "Nosso Futuro Comum", em 1987, e a Conferência das Nações Unidas sobre o Meio Ambiente e o Desenvolvimento (Rio 92), o volume de publicações começou a crescer, com destaque para o período posterior a 2003, quando o número ultrapassou definitivamente a marca de 100 artigos publicados por ano nesta base de dados e, ainda mais intensamente, a partir de 2010.

De fato, Della Giustina (2013, p. 193) afirma que "já há informação e propostas suficientes para a imediata implementação de políticas públicas conservacionistas" no Cerrado. No entanto, o autor conclui que essas políticas só serão colocadas em prática quando "o Estado e a sociedade incorporarem a questão ambiental como parte das ações fundamentais dos governos, das instituições e das pessoas". Apesar da grande quantidade de publicações sobre o bioma nos periódicos da base Web of Science, percebe-se que a penetração desses conteúdos na sociedade e, por conseguinte, na agenda governamental, ainda é insatisfatória.

Em seguida, o estudo focalizou as principais áreas de pesquisa dos artigos que mencionaram o bioma Cerrado, a fim de verificar o escopo dessas publicações.

Na Figura 2, observa-se a predominância de áreas voltadas às ciências biológicas, como "plant sciences", "ecology" e "zoology". Sachs (2008, p. 130) argumenta que "nenhum outro país do mundo reúne condições igualmente favoráveis à criação gradual de uma nova civilização sustentável dos trópicos, baseada na exploração sistemática do trinômio biodiversidade biomassas - biotecnologias", algo que pode referendar a predileção de cientistas ligados à biologia e à ecologia pela exploração científica do imensurável potencial presente no Cerrado. Além disso, áreas como biologia molecular e genética reforçam a ideia de que essas virtudes têm sido aproveitadas pela Academia.

Em contrapartida, áreas de pesquisa relacionadas às ciências sociais aplicadas, como as políticas públicas e as ciências econômicas, por exemplo, não foram contempladas. A transformação proposta por Sachs, e que permeia a discussão do desenvolvimento sustentável, obrigatoriamente passa por uma reorientação da economia e da maneira como os governos, empresas e demais organismos enxergam os recursos naturais disponíveis no país, no sentido de preservar o capital natural - e, quando utilizado, que isso aconteça mediante padrões auditáveis de sustentabilidade ambiental, permitindo sua preservação. 
Retomando o exposto por Fernandes e Pessôa (2011), essa mudança acontecerá mediante um incremento no número de estudos e publicações científicas acerca do Cerrado. Por isso, a abordagem de temas como os biomas brasileiros em estudos socioeconômicos pode gerar, além de um impacto inovador na Academia, resultados positivos para o desenvolvimento sustentável do Brasil.

Figura 2: Principais áreas de pesquisa dos artigos sobre o Cerrado na base Web of Science (1960-2019)

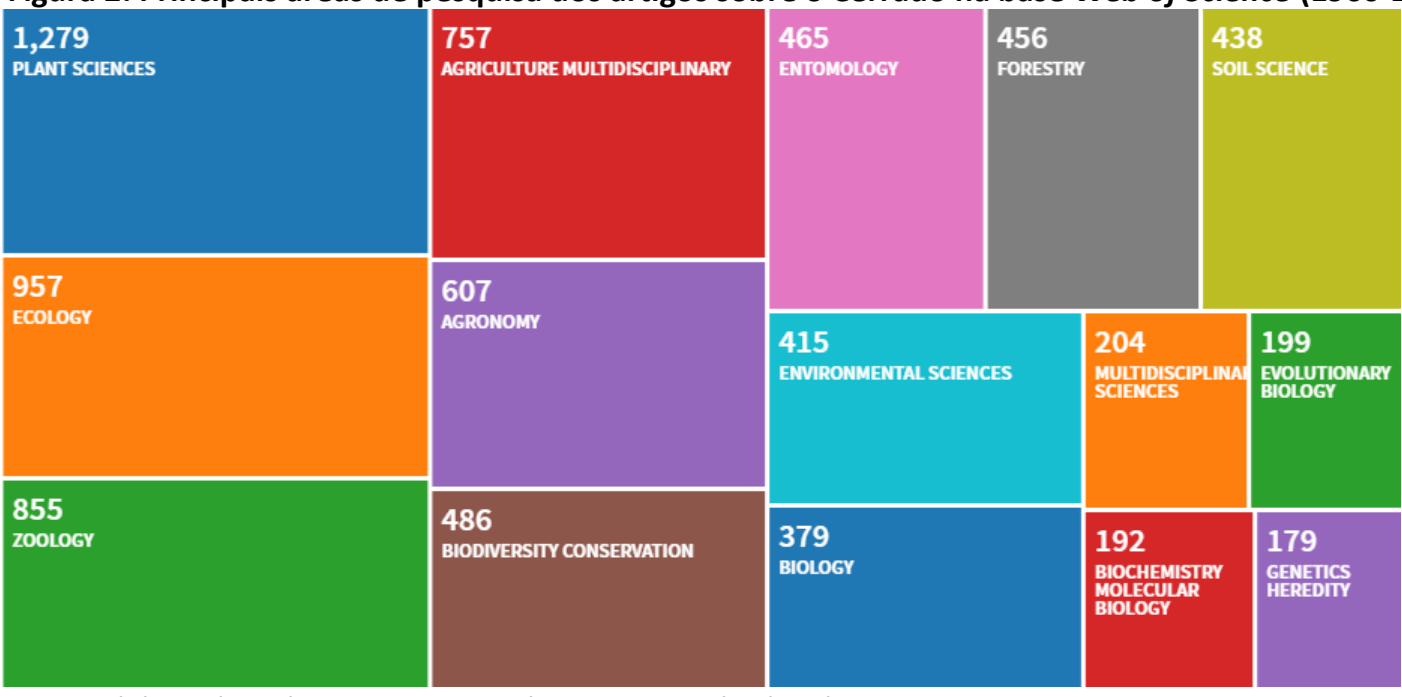

Fonte: Elaborado pelos autores, com base nos resultados da pesquisa.

Enfocando as 20 revistas científicas com maior número de publicações no período analisado, novamente não há destaque para journals de ciências sociais aplicadas, como demonstrado pela Tabela 2.

Essa constatação não deve considerada negativa. Uma vez que as ciências biológicas são contempladas, resultando em significativa produção científica de catalogação da fauna e flora do bioma analisado, é possível compreendê-lo cada vez mais e permitir investimentos em sua conservação e utilização de maneira sustentável.

Ainda assim, isso expõe uma lacuna de pesquisa a ser explorada por cientistas sociais, economistas, administradores públicos e, até mesmo, antropólogos, tendo em vista que "muitas populações sobrevivem de seus recursos naturais [do Cerrado], incluindo etnias indígenas, quilombolas, geraizeiros, ribeirinhos, babaçueiras, vazanteiros e comunidades quilombolas que, juntas, fazem parte do patrimônio histórico e cultural brasileiro" (MINISTÉRIO DO MEIO AMBIENTE, 2020, s. p.).

Caso o estudo do Cerrado e de outros biomas não seja realizado de maneira inter ou transdisciplinar, como acontece na Economia Ecológica e na Sustentabilidade, por exemplo, um imenso potencial pode estar sendo desperdiçado.

Nesse sentido, a transição para uma economia de baixo carbono, a geração de empregos verdes e outras maneiras de se incrementar o bem-estar dos seres humanos, sem que isso comprometa o meio ambiente, podem ser formuladas a partir da confluência entre variadas áreas do conhecimento e a compreensão do Cerrado, algo passível de ser replicado em outros biomas também pressionados pela ação antrópica, como a Floresta Amazônica e a Mata Atlântica. 
Tabela 2: 20 periódicos com o maior número de publicações sobre o bioma Cerrado (1960-2019)

\begin{tabular}{|c|c|c|}
\hline Título do periódico científico & registros & $\%$ of 7498 \\
\hline Pesquisa Agropecuária Brasileira & 292 & 3.894 \\
\hline Revista Brasileira de Ciência do Solo & 179 & 2.387 \\
\hline Zootaxa & 157 & 2.094 \\
\hline Bioscience Journal & 145 & 1.934 \\
\hline Biota Neotropica & 128 & 1.707 \\
\hline Acta Botanica Brasilica & 127 & 1.694 \\
\hline Brazilian Journal of Biology & 124 & 1.654 \\
\hline Phytotaxa & 112 & 1.494 \\
\hline Revista Árvore & 88 & 1.174 \\
\hline Revista Brasileira de Ornitologia & 79 & 1.054 \\
\hline Anais da Academia Brasileira de Ciências & 78 & 1.040 \\
\hline Plos One & 76 & 1.014 \\
\hline Neotropical Entomology & 74 & 0.987 \\
\hline Sociobiology & 74 & 0.987 \\
\hline Semina Ciências Agrárias & 69 & 0.920 \\
\hline Biotropica & 68 & 0.907 \\
\hline Ciência Florestal & 68 & 0.907 \\
\hline Revista Brasileira de Entomologia & 68 & 0.907 \\
\hline Flora & 66 & 0.880 \\
\hline Revista Brasileira de Engenharia Agrícola e Ambiental & 63 & 0.840 \\
\hline Ciência e Agrotecnologia & 61 & 0.814 \\
\hline Iheringia Série Zoologia & 61 & 0.814 \\
\hline Genetics and Molecular Research & 57 & 0.760 \\
\hline Revista Brasileira de Fruticultura & 57 & 0.760 \\
\hline Ciência Rural & 56 & 0.747 \\
\hline
\end{tabular}

Fonte: Elaborado pelos autores, com base nos resultados da pesquisa. 
Como esperado, ao verificar a produção científica por país, o Brasil desponta isoladamente com o maior número de publicações, seguido à distância pelos Estados Unidos da América e por países europeus como Inglaterra, França e Alemanha. A presença dessas nações na lista demonstra que a importância do Cerrado para a biodiversidade do planeta extrapola as fronteiras do país no qual está inserido, reforçando a singularidade de sua fauna e flora.

A disposição dos 15 países em ordem de produção científica sobre o Cerrado na base de dados explorada encontra-se na Figura 3.

Figura 3: 15 países com a maior produção científica sobre Cerrado na base Web of Science (1960-2019)

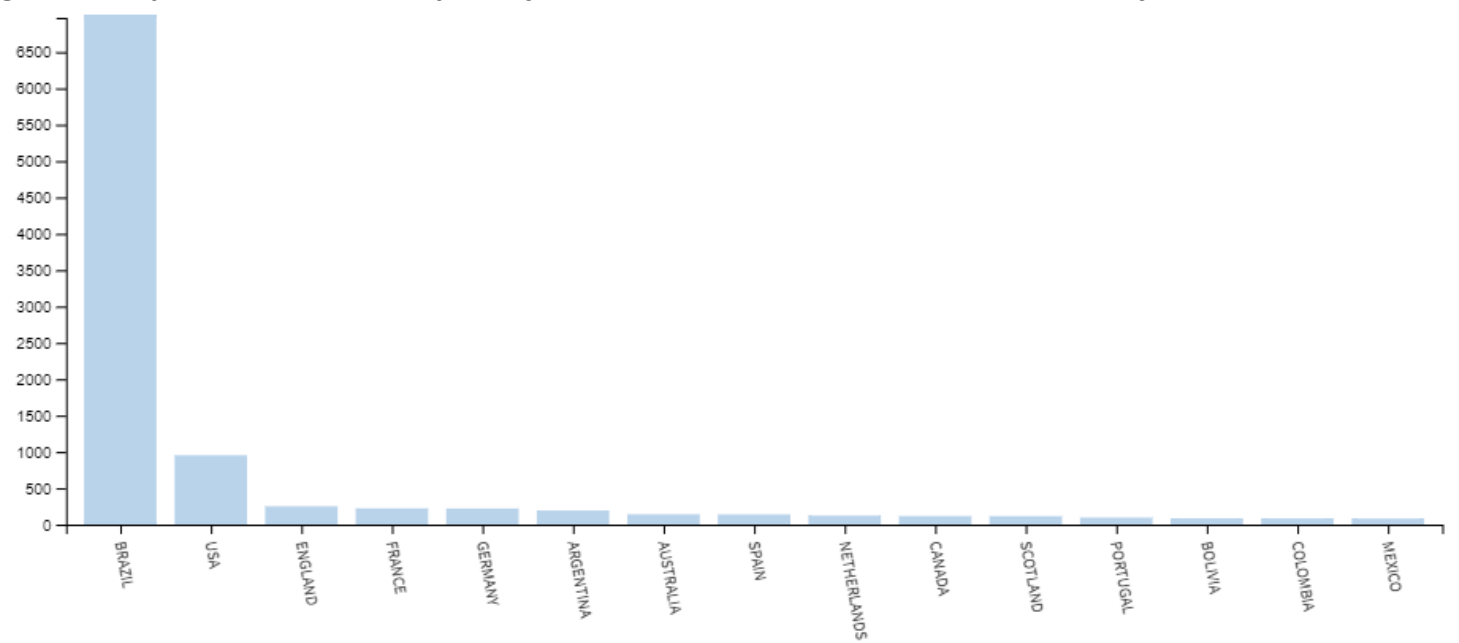

Fonte: Elaborado pelos autores, com base nos resultados da pesquisa.

Reafirmando a preponderância brasileira nos estudos científicos sobre o Cerrado, as Instituições de Ensino Superior cujos pesquisadores mais publicaram são a Universidade de Brasília (UnB) que, desde 2005, mantém o Centro UnB Cerrado na cidade de Alto Paraíso de Goiás (UNB CERRADO, 2016) e o periódico científico Revista Cerrados - seguida da Universidade de São Paulo (USP) e da Universidade Federal de Goiás (UFG).

Destacam-se, ainda, órgãos governamentais como a EMBRAPA Cerrados, ligada à Empresa Brasileira de Pesquisa Agropecuária (EMBRAPA).

Essas informações encontram-se no ranking organizando na Figura 4, que apresenta as 15 instituições com o maior número de publicações sobre o bioma cerrado na base Web of Science, no período analisado. 
Figura 4: 15 Instituições de Ensino Superior e institutos de pesquisa com o maior número de publicações sobre o bioma Cerrado (1960-2019)

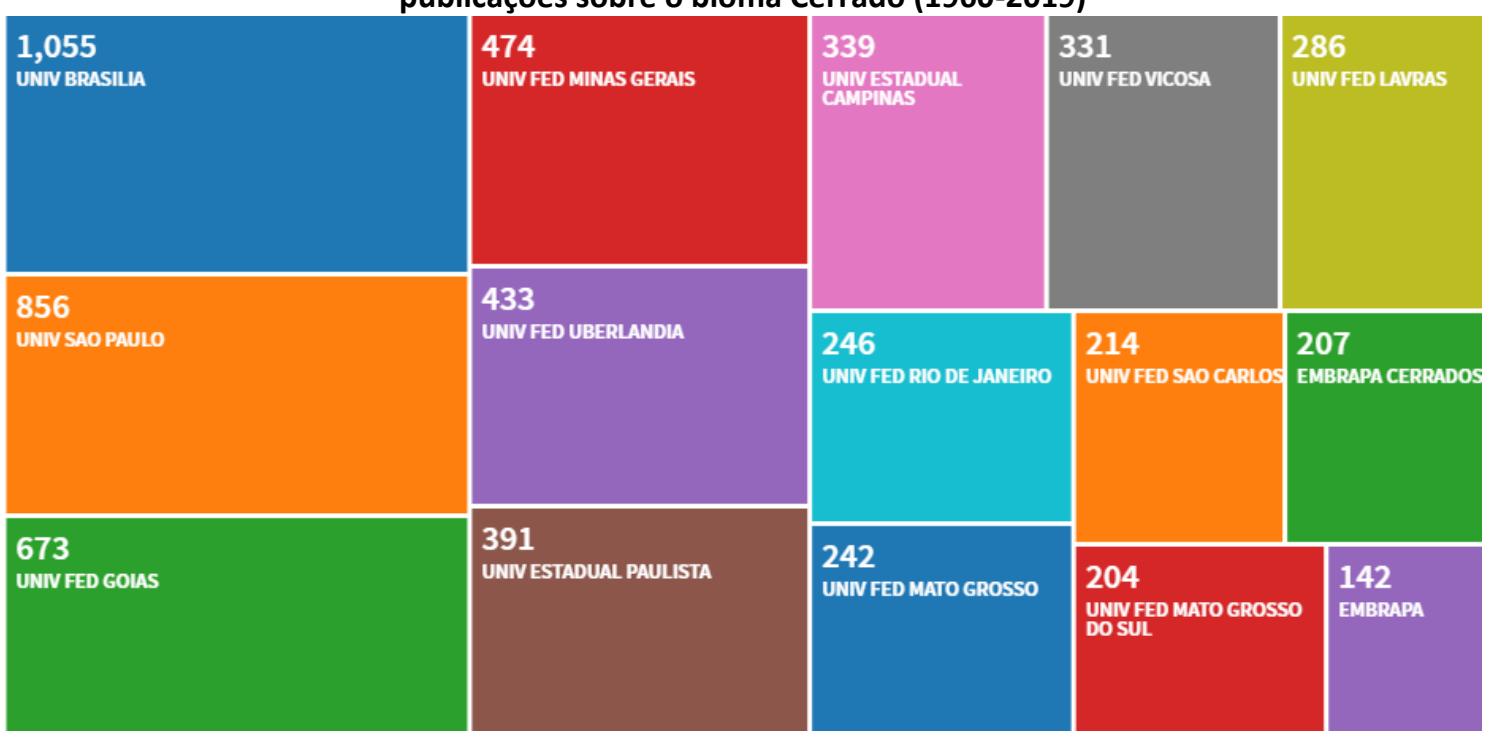

Fonte: Elaborado pelos autores, com base nos resultados da pesquisa.

\section{CONSIDERAÇÕES FINAIS}

O presente artigo explorou a produção científica em periódicos internacionais da base de dados Web of Science acerca do bioma Cerrado, que compreende cerca de $22 \%$ do território brasileiro, apresenta uma fauna e flora abundante e incomparável, mas que, em contrapartida, historicamente tem padecido por uma intensa exploração de seus recursos naturais, sobretudo nos últimos setenta anos, como consequência de uma vertiginosa urbanização.

A análise bibliométrica destacou que a produção científica sobre o Cerrado está em ascensão, com destaque para a última década, na qual o assunto foi abordado com maior profusão nos periódicos da base verificada.

Também, destacou-se a notória predominância de artigos publicados em periódicos voltados às ciências biológicas e à ecologia, em detrimento de áreas interdisciplinares como as ciências sociais aplicadas. Com isso, apresenta-se uma lacuna de pesquisa à comunidade científica, que carece de estudos que explorem o Cerrado e a manutenção do capital natural presente neste bioma sob a ótica das políticas públicas ou da economia, de maneira a fomentar novas maneiras de reduzir os impactos antrópicos nesse ecossistema natural e fortalecer ações governamentais e de organizações da sociedade civil que atuam no local, no sentido do desenvolvimento sustentável.

Finalmente, ao destacar as origens dos artigos selecionados, observou-se uma concentração da produção no Brasil. E, tratando-se das Instituições de Ensino Superior e dos institutos de pesquisa que mais publicaram, três Universidades públicas sobrelevam-se: Universidade de Brasília (UnB), Universidade de São Paulo (USP) e Universidade Federal de Goiás (UFG).

Como limitação desta pesquisa, ressalta-se a restrição das buscas a somente uma base de dados, Web of Science. Contudo, a amostra compreendeu publicações dos principais periódicos nacionais e internacionais que abordam o tema, evidenciando que, ainda que restrita, a pesquisa apresenta alto potencial para a elaboração de referenciais teóricos sobre o assunto, por permitir 
uma compreensão do estado da arte sobre a produção científica que aborda o Cerrado. Estudos posteriores podem analisar a mesma variável em outras bases de dados, a fim de confirmar ou refutar as conclusões alcançadas no presente artigo.

\section{AGRADECIMENTOS}

O presente trabalho foi realizado com apoio da Coordenação de Aperfeiçoamento de Pessoal de Nível Superior - Brasil (CAPES) - Código de Financiamento 001.

\section{REFERÊNCIAS BIBLIOGRÁFICAS}

AGÊNCIA BRASIL. Distrito Federal registra desigualdade maior que restante do país. 17 nov. 2018. Disponível em: https://agenciabrasil.ebc.com.br/economia/noticia/2018-11/distrito-federal-registradesigualdade-maior-que-restante-do-pais. Acesso em: 15 mai. 2020.

BRASIL. Câmara dos Deputados. Proposta de Emenda à Constituição 504/2010. Altera o § 4ㅇ do art. 225 da Constituição Federal, para incluir o Cerrado e a Caatinga entre os biomas considerados patrimônio nacional. Disponível em:

https://www.camara.leg.br/proposicoesWeb/fichadetramitacao?idProposicao=483817. Acesso em: 12 mai. 2020.

CEBRAP. Métodos de Pesquisa em Ciências Sociais. Bloco Quantitativo. São Paulo: Sesc-CEBRAP, 2016. Disponível em: http://bibliotecavirtual.cebrap.org.br/arquivos/2017_E-BOOK\%20Sesc-

Cebrap_\%20Metodos\%20e\%20tecnicas\%20em\%20CS\%20-\%20Bloco\%20Quantitativo.pdf. Acesso em: 31 mar. 2020.

CHUEKE, G. V.; AMATUCCI, M. O que é bibliometria? Uma introdução ao Fórum. Internext, São Paulo, v. 10, n. 2, p. 1-5, mai./ago. 2015. Disponível em: https://internext.espm.br/internext/article/view/330. Acesso em: 12 mai. 2020.

DALY, H. E. Crescimento sustentável? Não, obrigado. Ambiente \& Sociedade, v. 7, n. 2, p. 197-202, 2004. Disponível em: https://www.scielo.br/scielo.php?script=sci_arttext\&pid=S1414753X2004000200012\&lng=pt\&tlng=pt. Acesso em: 12 mai. 2020.

DELLA GIUSTINA, C. C. Degradação e Conservação do Cerrado: uma história ambiental do estado de Goiás. 2013. Tese (Doutorado em Desenvolvimento Sustentável) - Centro de Desenvolvimento Sustentável, Universidade de Brasília (UnB).

FERNANDES, P. A.; PESSÔA, V. L. S. O Cerrado e suas atividades impactantes: uma leitura sobre o garimpo, a mineração e a agricultura mecanizada. OBSERVATORIUM: Revista Eletrônica de Geografia, v. 3, n. 7, p. 19-37, out. 2011.

GEORGESCU-ROEGEN, N. O decrescimento: Entropia, ecologia e economia. São Paulo, SP: Editora Senac, 2012.

GIL, A. C. Métodos e técnicas de pesquisa social. 6. ed. São Paulo: Atlas, 2008.

KINGDON, J. W. Agendas, Alternatives and Public Policies. Pearson Education Limited, 2014.

MINISTÉRIO DO MEIO AMBIENTE. Mudanças climáticas X Biodiversidade - Inter - Relações entre Biodiversidade e Mudanças Climáticas. Brasília - DF: Biodiversidade -28, 2007. 219p. 


\section{Revista Científica ANAP Brasil}

ISSN 1984-3240 - Volume 13, número 31, 2020

MINISTÉRIO DO MEIO AMBIENTE. Biodiversidade Brasileira. 2020a. Disponível em:

https://www.mma.gov.br/biodiversidade/biodiversidade-brasileira. Acesso em: 10 mai. 2020.

MINISTÉRIO DO MEIO AMBIENTE. O Bioma Cerrado. 2020b. Disponível em:

https://www.mma.gov.br/biomas/cerrado.html. Acesso em: 14 abr. 2020.

QUEVEDO-SILVA, F.; SANTOS, E. B. S.; BRANDÃO, M. M.; VILS, L. Estudo bibliométrico: Orientações sobre sua aplicação [Bibliometric study: Guidelines on its application]. Revista Brasileira de Marketing: REMARK, v. 15, n. 2, p. 246-262, 2016. Disponível em:

https://periodicos.uninove.br/index.php?journal=remark\&page=article\&op=view\&path\%5B\%5D=12129. Acesso em: 15 mai. 2020.

SACHS, I. Desenvolvimento includente, sustentável, sustentado. Rio de Janeiro: Garamond, 2008, 151 p.

SOCIEDADE BRASILEIRA DE ECONOMIA ECOLÓGICA. O que é a Economia Ecológica? 2020. Disponível em: http://ecoeco.org.br/economia-ecologica/. Acesso em: 05 mai. 2020.

SOUZA, C. Políticas públicas: uma revisão da literatura. Sociologias, Porto Alegre, n. 16, p. 20-45, 2006. Disponível em: http://www.scielo.br/scielo.php?script=sci_abstract\&pid=S1517-

$45222006000200003 \&$ Ing=en\&nrm=iso\&tlng=pt. Acesso em: 12 mai. 2020.

UNB CERRADO. 2016. Disponível em: http://www.unbcerrado.unb.br/. Acesso em: 14 abr. 2020.

WORLD COMMISSION ON ENVIRONMENT AND DEVELOPMENT. Our common future: The World Commission on Environment and Development. Oxford: Oxford University Press, 1987.

WWF. Ameaças ao Cerrado. 2020. Disponível em:

https://www.wwf.org.br/natureza_brasileira/questoes_ambientais/biomas/bioma_cerrado/bioma_cerr ado_ameacas/. Acesso em: 10 mai. 2020. 